\title{
AUTOMATIC CONTROL IN ELECTRICAL EQUIPMENT MONITORING BY USING PLC PROGRAMMING TECHNOLOGY
}

\author{
Zhi Li ${ }^{1}$ \\ ${ }^{1}$ Sichuan Equipment Manufacturing Industry Robot, Application Technology Engineering Laboratory, \\ Deyang, Sichuan 618000, China \\ Email: lzlimail@163.com
}

\begin{abstract}
Programmable logic controller (PLC) programming technology plays an important role in the automatic control of industrial electrical equipment monitoring. Based on PLC programming technology and taking transformer air-cooled equipment as the subject, a control system of aircooled equipment based on PLC was designed, the hardware and software design of the system was introduced, and simulation experiments were carried out. The experiment found that the air-cooled control system could operate normally at high and low temperatures, the daily power consumption was lower than the traditional control system, it could realize the automatic switching of air-cooled equipment by monitoring the temperature of transformer to save energy. The experiment proves the validity of PLC in the automatic control of air-cooling system and makes some contributions to the better application of PLC technology in electrical equipment.
\end{abstract}

Keywords: Programmable Logic Controller Programming; Electrical Equipment; Monitoring; Automatic Control.

\section{Introduction}

With the rapid development of society, the requirements and standards for industrial production are also rising [1]. Therefore, the study of automatic control in electrical equipment monitoring is very important. Combining with some new methods [2], such as programmable logic controller (PLC) programming technology, noncontact electrostatic detection technology, fundamental resistance current method and distributed control system can monitor electrical equipment conveniently and effectively and automatically control them, so as to improve and optimize the monitoring mechanism of electrical equipment and further improve the monitoring ability of electrical equipment and enhance the ability of automatic control [3]. In response to this problem, many experts and scholars have put forward their own views. Lan [4] put forward the application of a kind of intelligent industrial robot control system based on PLC in mechanical automation and proved that the method ran accurately and reasonably, improved the work efficiency, and reduced workers' work repetition. Mahato et al. [5] considered that the remote monitoring and control applications of industrial systems in the past were limited, which made it impossible to access control systems from multiple locations. Therefore, an embedded Web PLC was proposed.
Hailesellasie and Hasan [6] proposed an industrial control system based on PLC which combined the formal verification method of intrusion detection with graphics to improve the performance of automatic control. Dominic et al. [7] proposed the PLC-based real-time implementation of flatness-based feedforward control (FFC) scheme, applied it to industrial gas compression system, and found that the flatness-based control design could be implemented in real compressor system. In this study, transformer air-cooled equipment was taken as the subject, an air-cooled control system was designed by applying PLC technology to the automatic control of air-cooled equipment, and the reliability of the system was proved through experiments. This work makes some contributions to the further development of the automatic control of electrical equipment.

\section{PLC Programming Technology}

PLC programming is an electronic system which operates through digital operation [8]. It is specially designed for industrial production [9]. It has advantages of simple and convenient operation, large capacity, functional diversity, favourable adaptability, strong reliability and high efficiency [10]; because of the advantages, it has been widely used in industrial fields. Its main working principle [11] is to control different types of mechanical equipment or industrial production process through 
internally storing using programmable memory, executing the commands of relevant operations such as logical operations, sequence control, counting, arithmetic operations, and timing and performing input and output operations. It is an important link in the field of industrial production.

The main components of PLC [12] include power module, central processing unit (CPU), interface circuit, input module, output module and programming equipment. Among them, the power module mainly includes: power-off protection power supply, standby power supply and system power supply[13], which makes the power module play a better role in providing power supply in industrial production; the main function of CPU is to store and make logic and mathematical operations[14]; the main function of interface circuit is convert the input signal and output signal to drive the field equipment by using input circuit and output circuit [15]. Figure 1 is a schematic diagram of the main working principle of PLC.

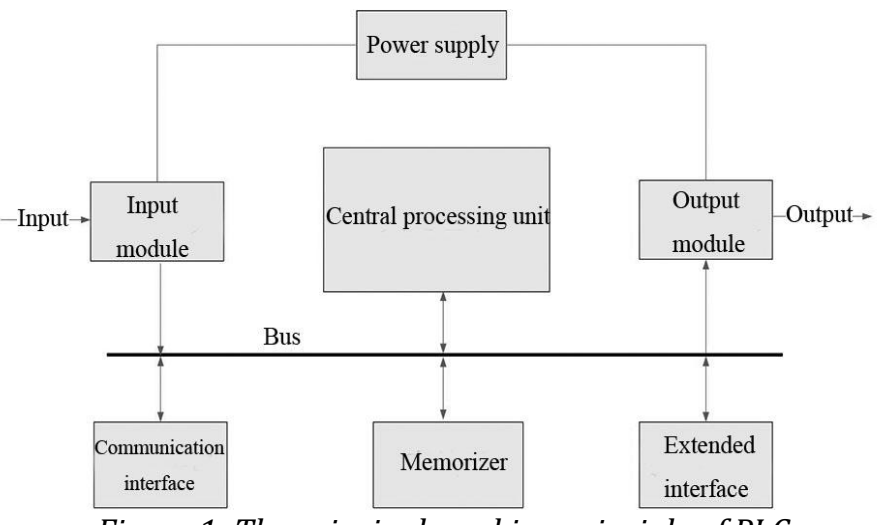

Figure 1: The principal working principle of PLC

\section{Automatic Control in Electrical Equipment Monitoring \\ 3.1 Application of PLC programming technology in automatic control}

By virtue of its good advantages in industrial application, PLC programming technology has been widely used in automatic control of electrical equipment monitoring. It can improve the storage capacity of electrical equipment, effectively store equipment data, and give full play to the intelligent effect of electrical equipment, so as to realize the independent production of equipment. Taking the electrical equipment of thermal power plant as an example, the study of the application of PLC programming technology in automatic control mainly includes: (1) sequential control: through PLC, it can realize the timely cleaning of coal ash and cinder by automation equipment and improve the working efficiency of coal conveying system; (2) switching quantity control: The virtual relay can be effectively controlled by PLC, which can shorten the response time of the system; (3) Closed-loop control: the automatic start-up of electrical equipment in thermal power plant can be realized by PLC, which can reduce the workload of human; (4) governor control: through PLC, different units of governor can be strictly controlled, which is conducive to the normal operation of the equipment.

\subsection{Application of PLC programming technology in air cooling control of power transformer}

\section{- Control mode of traditional air-cooled equipment}

Power transformer will emit a lot of heat in the process of working, which will lead to copper loss, iron loss and other loss phenomena of transformer, and it is not conducive to the stable operation of transformer. Reliable equipment is needed to achieve heat dissipation. Air-cooled equipment has excellent heat dissipation effect, which is a widely used heat dissipation method at present. The traditional air-cooled equipment usually adopts relay logic judgment method to control the equipment, which needs a large number of relays and has a complex control loop. Moreover the failure rate of relays is high, and the maintenance task is heavy. With the development of electronic system, the control mode of the traditional air-cooled equipment can not meet people's needs. The automatic and intelligent control technology is urgently needed to realize the monitoring of aircooled equipment.

\section{- Overall design of PLC air-cooled control system}

In this study, an air-cooled control system is designed by using PLC programming technology. The automatic control of the air-cooled system is realized 
by monitoring the temperature change of transformer and the operation state of air-cooling. The PLC air-cooled control system designed in this study can mainly achieve the following functions:

(1) Voltage/current acquisition. The system can collect the fan's voltage/current data in real time and transmit it to the upper computer, so that the staff can understand the data changes in time and locate the fault accurately.

(2) State information acquisition. The system can collect the state information of high and low temperatures of the air-cooled equipment and start and stop of electric fan and complete the control function of the equipment.
(3)Automatic control. The system can automatically start and stop fans and pumps according to voltage/current information and switching status.

(4) Remote monitoring. The system can realize the real-time monitoring of the air-cooled equipment by staffs, so as to deal with the equipment failure in time.

(5) Fault alarm. The system can realize the selfchecking function of power failure and data preservation errors and prompt staffs in time.

The overall framework of PLC air-cooled control system is shown in Figure 2.

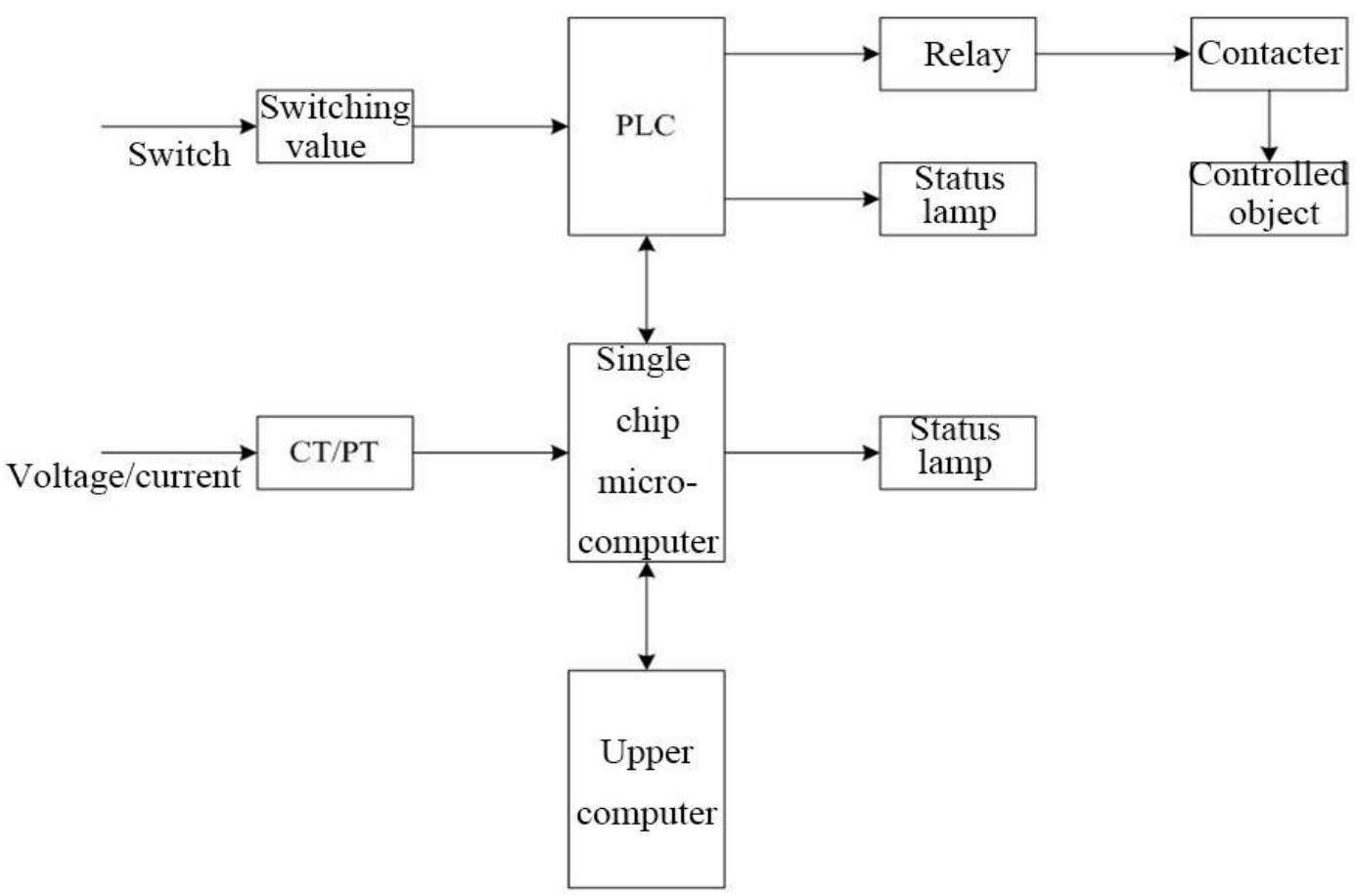

Figure 2: PLC air-cooled control system

The system is mainly composed of three parts: (1) PLC: it is the main control equipment of the system, which determines system state through the collected data, sends control signals to control the operation state of fan, and transfers state and commands; (2) single chip microcomputer: the main task of single chip microcomputer is to collect voltage/current signals, realize communication between PLC and upper computer, and diagnose the current system state; (3) the upper computer: the upper computer is responsible for displaying the information conveyed by the single chip microcomputer through the interface, setting different parameters of the system, and storing the system alarm status.
Each part of the system is connected by the control board and installed in the cabinet with the standard $4 \mathrm{U}$ cabinet back-inserted design, which can not only ensure the installation space of the equipment, but also help to control the heat dissipation of the cabinet.

\section{- Hardware design}

(1) Power module

The power supply module of the system adopts AC-DC military grade module power supply, and the switching of power supply uses double power automatic switching switch. Its principle is shown in Figure 3. 


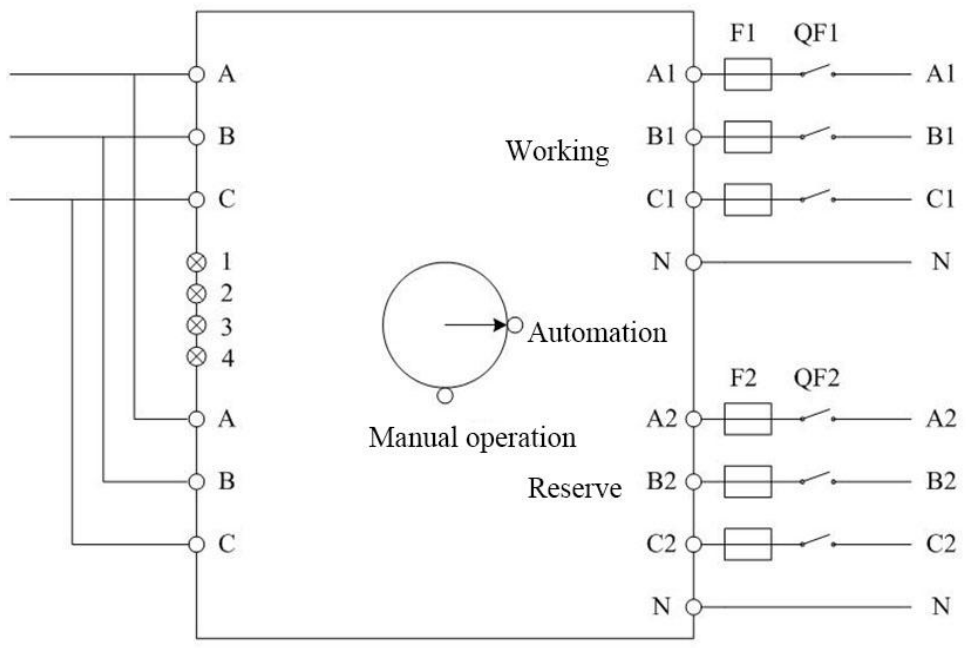

Figure 3: The schematic diagram of power switching

The switch can switch the working power supply and reserve power supply freely. QF1 and QF2 represent the power supply circuit breaker, 1 and 2 are fault indicator lights for working and reserve power supply, and 3 and 4 are normal indicator lights for working and reserve power supply.

(2) PLC module

The PLC used in the system is Siemens S7-200 PLC small-sized PLC, which is cheap, powerful and easy to use. Under Windows environment, the programming and debugging of the PLC can be realized through the supporting STEP7 programming software, which fully meets the requirements of the air-cooled control system in this study. PLC has a data memory with 10240 bytes and is inserted with a timing clock. The power-down protection time is 100 hours. There are seven extended modules. The Boolean execution speed is 0.22 milliseconds/command.
(3) Single ship microcomputer module

The single ship microcomputer used in the system is MSP430, which communicated with PLC and upper computer through RS485. The power circuit is $5 \mathrm{~V}-3.3 \mathrm{~V}$. The link between single chip microcomputer and motherboard is realized through two 32-pin European sockets.

\section{- Software design}

(1) Main Programming

The main function of the main program is to realize the communication between the PLC and the host computer, judge the collected information, execute the subroutine, and realize the monitoring and control of the air-cooled equipment. The main program design is shown in Figure 4.

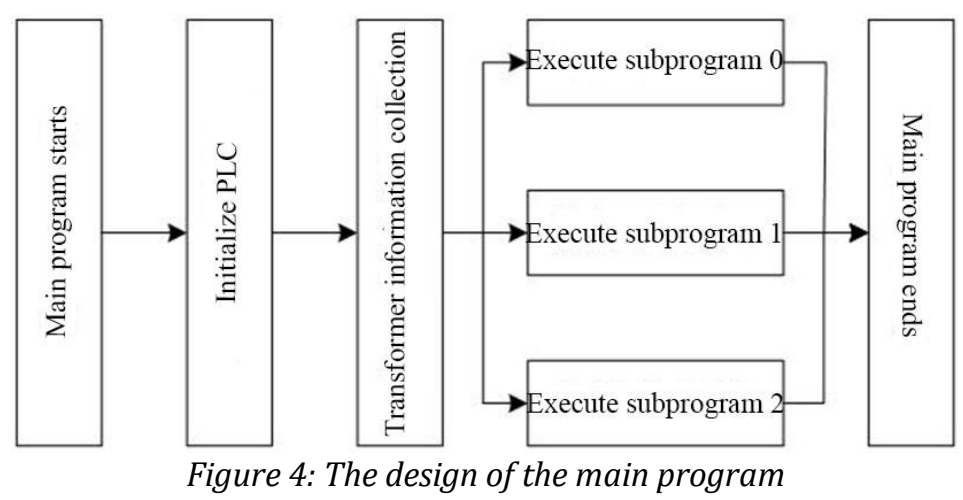

(2) Subprogramming

(1) Subprogram 0

The main function of subprogram 0 is to switch equipment according to the oil temperature of transformer top layer and the cumulative running time and cumulative stopping time of air-cooled equipment. Its operation steps are as follows:

(1) Subprogram 0 begins.
(2) Whether the oil temperature is higher than $75^{\circ} \mathrm{C}$ is determined. If not, it returns to the previous step; if it is, the air-cooled equipment with the longest stopping time is input for the heat dissipation of transformer.

The operation is delayed for 10 minutes. The oil temperature is determined again. If the temperature is still higher than $75^{\circ} \mathrm{C}$, the air-cooled equipment is 
continuously input until the oil temperature is lower than the upper limit.

(4) Whether there is a fault in the air-cooled equipment is determined. If there is, the reserve equipment is input; otherwise, the equipment continues operation.

(5) Whether the oil temperature is lower than $45^{\circ} \mathrm{C}$ is determined. If it is, a set of air-cooled equipment with the longest running time is cut off.

(6) The operation is delayed for 10 minutes. The oil temperature is determined again. If it is still lower than $45^{\circ} \mathrm{C}$, the equipment is cut off until the oil temperature is higher than the lower limit.

(7) Subprogram 0 ends.

(2) Subprogram 1

The main function of subprogram 1 is to determine whether the transformer is overloaded or winding is overheated and to switch the air-cooled equipment. Its operation steps are as follows:

(1) Subprogram 1 begins.

(2) Whether the transformer has overload or the winding has overheating is determined. If it does not, it returns to the previous step; if it does, the off-duty air-cooling equipment is started.

(3) Whether there is a fault in the air-cooled equipment is determined. If there is, the reserve equipment is input; otherwise, the operation continues.

(4) Whether the transformer has overload and the winding has overheat is determined. If it does, it returns to the previous step; if not, the added aircooled equipment is cut off.

(5) Subprogram 1 ends.

(3) Subprogram 2

The main function of subprogram 2 is to start the protection of transformer when the air-cooled equipment stops due to failure. Its operation steps are as follows:

(1) Subprogram 0 begins.

(2) Whether the air-cooled equipment in the system stops completely due to the failure is determined. If not, it returns to the previous step; if it does, it turns to the next step.

(3) Whether the oil temperature of the transformer is higher than $75^{\circ} \mathrm{C}$ at this moment is determined. If not, the transformer is allowed to continue running for one hour; if it is, the transformer is allowed to continue running for 20 minutes, and then the transformer is cut off.

(4) Subprogram 2 ends.

\section{Simulation Experiment 4.1 Equipment automation control test}

The transformer environment was simulated to $78^{\circ} \mathrm{C}$ The automatic control process of the system is as follows.

(1) A set of air-cooled equipment with the longest stopping time was input and ran for $10 \mathrm{~min}$.
(2) When the temperature decreased to $76^{\circ} \mathrm{C}$, the second set of equipment with the longest stopping time was input and ran for $10 \mathrm{~min}$.

(3) When the temperature decreased to $70^{\circ} \mathrm{C}$, the input equipment stopped.

(4) When the temperature decreased to $40^{\circ} \mathrm{C}$, a set of equipment with the longest operation time was cut off, and the operation continued for $10 \mathrm{~min}$.

(5) When the temperature increased to $42^{\circ} \mathrm{C}$, the second set of equipment with the longest operation time was cut off, and the operation continued for 10 $\min$.

(6) When the temperature increased to $46^{\circ} \mathrm{C}$, the cutting-off equipment stopped.

The complete failure condition of the air-cooled equipment was simulated. The automatic control process of the system is as follows.

(1) The current operation condition of the aircooled equipment is determined, and it was found that the equipment failed and stopped.

(2) It was found that the oil temperature of transformer reached $78^{\circ} \mathrm{C}$ at that time.

(3) The transformer was cut off after 20 minutes of operation.

It was found that the automatic control system could realize the automatic control of air-cooled equipment through various information of transformer.

\subsection{High and low temperature experiments}

The heat dissipation problem of air-cooled equipment of transformer is difficult to solve, so the equipment needs to have enough high temperature and low temperature resistance. Firstly, the equipment was tested at high temperature. The temperature in the test box was gradually adjusted to $75^{\circ} \mathrm{C}$ The high temperature and overcurrent were simulated to check the data of single chip microcomputer and check whether the system ran normally. After three days of high temperature experiment, it was found that the system was always in normal operation.

After the high temperature experiment, the temperature of the equipment was lowered to $-25^{\circ} \mathrm{C}$ by reducing $15{ }^{\circ} \mathrm{C}$ every 30 minutes, and the operation status of the system was checked.

After three days of low temperature test, it was found that there was no false alarm or missed alarm, and the system could always maintain normal operation.

\subsection{Comparison with the traditional system}

The system designed in this study and the traditional system were simulated, and the daily power consumption of the two systems was calculated. The results are shown in Figure 5. 


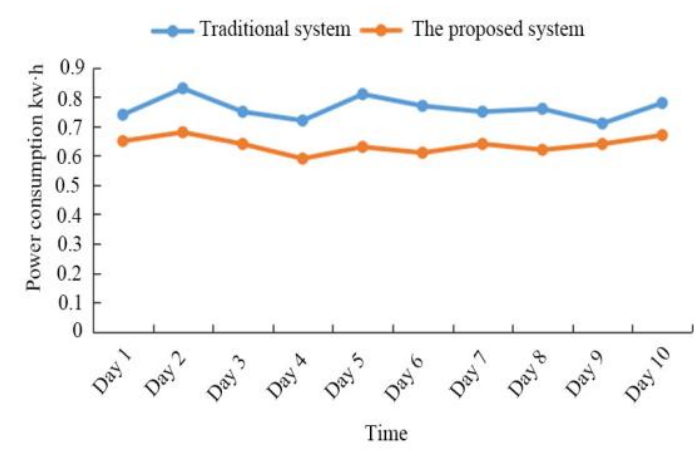

Figure 5: Comparison of daily power consumption
It was found from Figure 4 that the daily power consumption of the system designed in this study was lower than that of the traditional system. In ten days, the total power consumption of the traditional system was $7.62 \mathrm{kw} \cdot \mathrm{H}$, and the total power consumption of the system designed in this study was $6.37 \mathrm{kw} \cdot \mathrm{h}$, which was $16.4 \%$ lower than that of the traditional system.

The starting time of the cooling equipment of the two systems was compared. Taking the ninth and tenth days as examples, the temperature data of transformer were collected, and the results are shown in Table 5.

Table 1. Temperature records at the ninth and tenth days

\begin{tabular}{|l|l|l|l|l|l|l|l|l|l|l|l|l|l|}
\hline & $0: 00$ & $2: 00$ & $4: 00$ & $6: 00$ & $8: 00$ & $10: 00$ & $12: 00$ & $14: 00$ & $16: 00$ & $18: 00$ & $20: 00$ & $22: 00$ & $0: 00$ \\
\hline $\begin{array}{l}\text { Ninth } \\
\text { days }\end{array}$ & $6^{\circ} \mathrm{C}$ & $5^{\circ} \mathrm{C}$ & $7^{\circ} \mathrm{C}$ & $9^{\circ} \mathrm{C}$ & $14^{\circ} \mathrm{C}$ & $25^{\circ} \mathrm{C}$ & $26^{\circ} \mathrm{C}$ & $28^{\circ} \mathrm{C}$ & $26^{\circ} \mathrm{C}$ & $24^{\circ} \mathrm{C}$ & $18^{\circ} \mathrm{C}$ & $10^{\circ} \mathrm{C}$ & $9^{\circ} \mathrm{C}$ \\
\hline $\begin{array}{l}\text { Tenth } \\
\text { days }\end{array}$ & $7^{\circ} \mathrm{C}$ & $6^{\circ} \mathrm{C}$ & $5^{\circ} \mathrm{C}$ & $9^{\circ} \mathrm{C}$ & $10^{\circ} \mathrm{C}$ & $14^{\circ} \mathrm{C}$ & $15^{\circ} \mathrm{C}$ & $16^{\circ} \mathrm{C}$ & $18^{\circ} \mathrm{C}$ & $16^{\circ} \mathrm{C}$ & $10^{\circ} \mathrm{C}$ & $9^{\circ} \mathrm{C}$ & $8^{\circ} \mathrm{C}$ \\
\hline
\end{tabular}

On the ninth day, the traditional system ran the first set of fans at 9:00 and the second set of fans at 10:00 and stopped the first set of fans at 19:00 and the second set of fans at 21:00.

The system ran the fan from 9:00 to 10:00 according to the designed program and then stopped the fan from 19:00 to 21:00.

On the tenth day, the traditional system operated the first set of fans at 9:00, but did not start the second set of fans because of the lower temperature on that day. The system also ran and stopped the fan in turn according to the set procedure.

In the case of high temperature, the air-cooled control system based on PLC designed in this study could intelligently switch equipment according to the temperature monitoring of transformer, maximize the use of each equipment, and achieve the effect of saving electricity. Therefore, the air-cooled control system designed in this study had better performance.

\section{Conclusions}

In this study, the application of PLC programming technology in automatic control of electrical equipment monitoring was studied. Taking the aircooled equipment of transformer as an example, an air-cooling control system based on PLC was designed, which could monitor the operation status of transformer through PLC and realize the automatic switching of air-cooled equipment.
This work is beneficial to realizing the automatic control of air-cooled equipment, and the designed system can be applied and promoted in practice.

\section{References}

[1] Kim I, Kim T, Sung M, Tisserant E, Bessard L, Choi C. "An open-source development environment for industrial automation with EtherCAT and PLC open motion control," 2013 IEEE 18th Conference on Emerging Technologies \& Factory Automation (ETFA), 2013.

[2] Rösch S, Vogel-Heuser B. "A Light-Weight Fault Injection Approach to Test Automated Production System PLC Software in Industrial Practice," Control Engineering Practice, 2017, 58 (Complete):12-23.

[3] Hennig C, Kneupner K, Kinna D. “Connecting programmable logic controllers (PLC) to control and data acquisition a comparison of the JET and Wendelstein 7-X approach," Fusion Engineering and Design, 2012, 87(12):19721976.

[4] Lan D C. "The Application of Intelligent Industrial Robotic Control System Based on PLC in Mechanical Automation," Advanced Materials Research, 2013, 738:272-275.

[5] Mahato B, Maity T, Antony J. "Embedded Web PLC: A New Advances in Industrial Control and Automation," Second International Conference on Advances in Computing \& Communication Engineering, 2015. 
[6] Hailesellasie M, Hasan S R. "Intrusion Detection in PLC-Based Industrial Control Systems Using Formal Verification Approach in Conjunction with Graphs," Journal of Hardware and Systems Security, 2017.

[7] Dominic S, Lohr Y, Schwung A, Ding S. "PLCbased Real-time Realization of Flatness-Based Feedforward Control for Industrial Compression Systems," IEEE Transactions on Industrial Electronics, 2016:1-1.

[8] Ahiska R, Mamur H. "A test system and supervisory control and data acquisition application with programmable logic controller for thermoelectric generators," Energy Conversion and Management, 2012, 64:15-22.

[9] Stone S J, Temple M A, Baldwin R O. "Detecting anomalous programmable logic controller behavior using RF-based Hilbert transform features and a correlation-based verification process," International Journal of Critical Infrastructure Protection, 2015, 9:41-51.

[10] Valencia-Palomo G, Rossiter J A. "Novel programmable logic controller implementation of a predictive controller based on Laguerre functions and multiparametric solutions," IET Control Theory \& Applications, 2012, 6(8):1003-1014.
[11] Mani P, Prasanna M. "Automatic test case generation for programmable logic controller using function block diagram," 2016 International Conference on Information Communication and Embedded Systems (ICICES), 2016.

[12] Chen S L, Chen I H, Shao H C, Chen W C, Chang H J. "Development of a Control System with Soft Programmable Logic Controller (I/O) Compiling Function Embedded and Applying into Automatic Optical Inspection System," Advanced Science Letters, 2012, 8(1):1-6.

[13] Ardi S, Al-Rasyid A. "Design of Pokayoke Sensor Systems in Drill Oil Hole Machine to Detect the Presence of Drill Using Programmable Logic Controller," Advanced Science Letters, 2016, 22(7):1813-1816.

[14] Putri T 0, Rahmadwati Siswojo B. “Temperature control of liquid egg pasteurization system using PLC (programmable logic controller) Siemens SIMATIC S7-200 and HMI (human machine interface) SIMATIC HMI panel," IEEE, 2015.

[15] Kumar L, Jetley R, Sureka A. "[ACM Press of the 7th International Workshop - Austin, Texas (2016.05.14-2016.05.22)] Proceedings of the 7th International Workshop on Emerging Trends in Software Metrics - WETSoM $\backslash$ "16Source metrics for ammable logic controller (PLC) ladder diagram (LD) visual programming," 2016:15-21. 